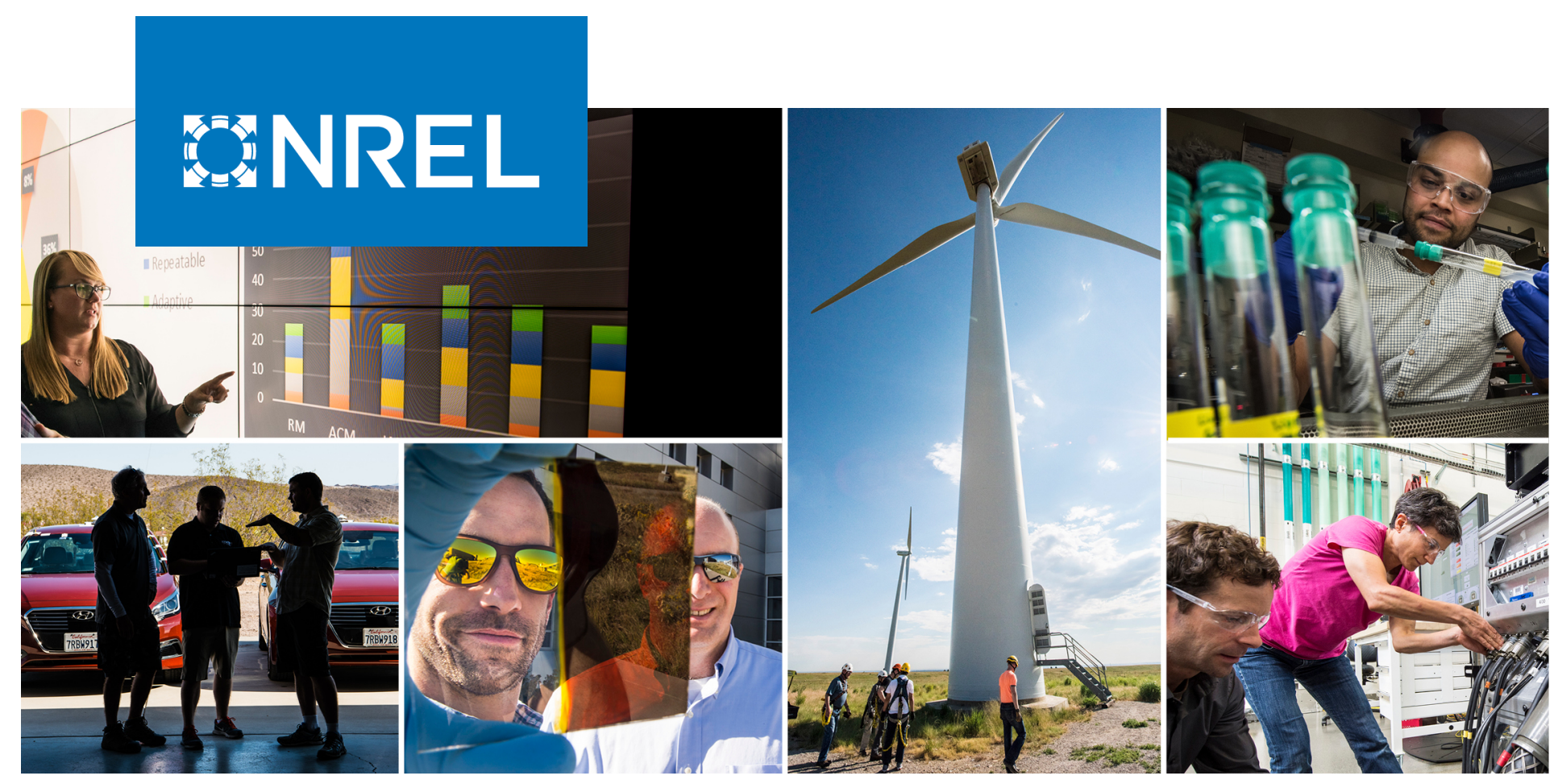

\title{
Acoustic and Genetic Approaches for Informing Population Status and Trends of Migratory Tree Bats
}

Cris Hein, ${ }^{1}$ Amanda Hale,${ }^{2}$ and Bethany Straw ${ }^{1}$

1 National Renewable Energy Laboratory

2 Texas Christian University

NREL is a national laboratory of the U.S. Department of Energy Office of Energy Efficiency \& Renewable Energy

Operated by the Alliance for Sustainable Energy, LLC

This report is available at no cost from the National Renewable Energy Laboratory (NREL) at www.nrel.gov/publications.
Technical Report

NREL/TP-5000-78563

April 2021 


\section{BNREL}

\section{Acoustic and Genetic Approaches for Informing Population Status and Trends of Migratory Tree Bats}

Cris Hein, ${ }^{1}$ Amanda Hale, ${ }^{2}$ and Bethany Straw ${ }^{1}$

1 National Renewable Energy Laboratory

2 Texas Christian University

\section{Suggested Citation}

Hein, Cris, Amanda Hale, and Bethany Straw. 2021. Acoustic and Genetic Approaches for Informing Population Status and Trends of Migratory Tree Bats. Golden, CO: National Renewable Energy Laboratory. NREL/TP-5000-78563.

https://www.nrel.gov/docs/fy210sti/78563.pdf.

NREL is a national laboratory of the U.S. Department of Energy Office of Energy Efficiency \& Renewable Energy Operated by the Alliance for Sustainable Energy, LLC

This report is available at no cost from the National Renewable Energy Laboratory (NREL) at www.nrel.gov/publications.

Contract No. DE-AC36-08GO28308
Technical Report NREL/TP-5000-78563 April 2021

National Renewable Energy Laboratory 15013 Denver West Parkway Golden, CO 80401 303-275-3000 • www.nrel.gov 


\section{NOTICE}

This work was authored in part by the National Renewable Energy Laboratory, operated by Alliance for Sustainable Energy, LLC, for the U.S. Department of Energy (DOE) under Contract No. DE-AC36-08GO28308. Funding provided by the U.S. Department of Energy Office of Energy Efficiency and Renewable Energy Wind Energy Technologies Office. The views expressed herein do not necessarily represent the views of the DOE or the U.S. Government.

This report is available at no cost from the National Renewable Energy Laboratory (NREL) at www.nrel.gov/publications.

U.S. Department of Energy (DOE) reports produced after 1991 and a growing number of pre-1991 documents are available free via www.OSTI.gov.

Cover Photos by Dennis Schroeder: (clockwise, left to right) NREL 51934, NREL 45897, NREL 42160, NREL 45891, NREL 48097, NREL 46526.

NREL prints on paper that contains recycled content. 


\section{Acknowledgments}

This report benefited from thoughtful input from T. Allison, J. Anderson, S. Cornman, W. Frick, N. Friedenberg, M. Khalil, B. Reichert, R. Thresher, T. Weller, and three anonymous reviewers. 


\section{List of Acronyms}

BWEC

EPRI

IUCN

mtDNA

NABat

RADseq

SNP

WNS
Bats and Wind Energy Cooperative

Electric Power Research Institute

International Union for the Conservation of Nature

mitochondrial DNA

North American Bat Monitoring Program

restriction-site associated DNA sequencing

single nucleotide polymorphism

White-nose Syndrome 


\section{Executive Summary}

Understanding the population structure and dynamics of bats is essential for assessing and mitigating risk and ensuring population viability. For many cave-roosting species, it is relatively easy to quantify and track populations because they congregate in large numbers during winter and can be monitored over time. However, for tree-roosting species, collecting and interpreting population data is challenging. These species do not aggregate in conspicuous locations but instead roost individually and are dispersed across the landscape, making it impractical for traditional surveys to provide estimates of census population sizes.

Several species of bats are exposed to both natural and human-induced environmental stressors resulting in population declines. For cave-roosting species, White-nose Syndrome has decimated populations. Conversely, wind turbines represent a potential population-level threat for migratory bats, such as hoary bats (Lasiurus cinereus), eastern red bats (L. borealis), and silver-haired bats (Lasionycteris noctivagans), given their relatively low reproductive rates and the level of documented mortality across wind energy facilities in North America.

Recent studies have assessed the potential population-level impact of wind energy facilities on hoary bats and given a set of assumptions for population growth rate and mortality rate from wind turbines, suggested a $38 \%$ reduction in turbine-related mortality is necessary to manage extinction risk for a starting population of 2.25 million bats. Reducing uncertainty in the model may not be immediately achievable as census data cannot be derived from existing methods. However, using a variety of techniques, including systematic acoustic sampling and genomic analysis, it is possible to build a weight of evidence on bat population trends and assess whether 1) mortality associated with wind turbines is sustainable, 2) minimal or substantial mitigation is required, and 3) mitigation measures are effective in ensuring population stability.

Consistent, long-term data collection remains the most reasonable option for reducing uncertainty and offering clarity into population trends for migratory tree-roosting bats. Using statistically robust methods for collecting acoustic data through the North American Bat Monitoring Program (NABat) or estimating effective population size at repeated intervals may provide data points over time to show species trends. Although there are no options for shortterm actions that will result in significantly reducing uncertainty, there is opportunity for relatively short-term investments that can support long-term success of data collection efforts.

For the wind energy industry, one option is to reallocate resources used for standard preconstruction acoustic monitoring to follow the NABat field methods and data submission protocols or provide funding support for NABat regional hubs in lieu of monitoring. Contributing to NABat will enable broad-scale inferences about bat populations. This approach has several additional benefits in that the data are not associated with a given wind energy project and the level of effort/cost, even for multiple years of data collection, may be equivalent to standard preconstruction acoustic surveys conducted in one year at a single wind energy project. There already is broad support for NABat, but the speed at which data are collected and available for analysis can be increased with support by the wind energy and wildlife community.

Another option is to invest resources to collect genetic samples from bats collected at wind energy facilities during postconstruction mortality monitoring. This collection should be targeted 
for migratory tree-roosting species at two different scales: 1) sample intensively in a few select geographic areas that have high expected levels of bat mortality; and 2) sample broadly across the United States to capture the rangewide level of impacts, which will ensure that we have sampled the entire population for each species. The collection, processing, and storage of tissue samples, and carcasses if available, would require cooperation and coordination that is above and beyond standard postconstruction mortality monitoring efforts. The anticipated cost of tissue sample collection and storage are not expected to be a barrier to participation, but additional funding sources will be required to conduct the genetic analyses.

Through the systematic collection of acoustic and genetic data over time, a weight of evidence may be built that will support an improved understanding around population stability for migratory tree-roosting bat species. This information can be leveraged to infer the influence stressors have on population stability, and subsequently determine the level of response necessary to sustain healthy populations. Here, we synthesize the existing information related to bat population status and trends, uncertainty regarding existing estimates, current and novel methods for assessing population-level data, and recommendations for near-term and long-term studies to reduce uncertainty surrounding population data. Although this report focuses on wind energy development and bats, the methods used are broadly applicable and are being implemented by other industries, academia, government agencies, and nongovernmental organizations. Through efforts outside of the wind energy industry, it is likely we will gain a better understanding of bat populations, but the pace of data collection and analysis will be expedited by further participation by the wind energy industry. In return, the wind energy industry will benefit by contributing to these efforts either by 1) discovering that the population status of the species of interest is stable or growing, which may prevent the need for listing one or more species; or 2) recognizing the population status of certain species is in decline and implementing relatively moderate measures to reduce wind turbine-related mortality in the near term to stave off more stringent measures, which may be necessary if action is delayed. 


\section{Table of Contents}

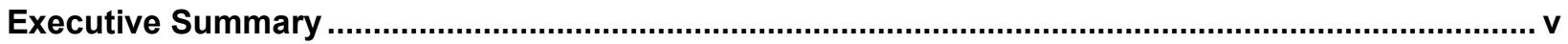

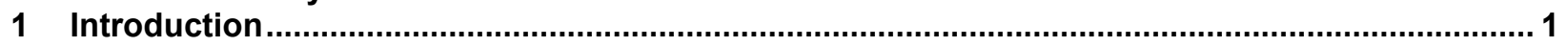

2 Population Monitoring Using Acoustic Surveys .................................................................... 5

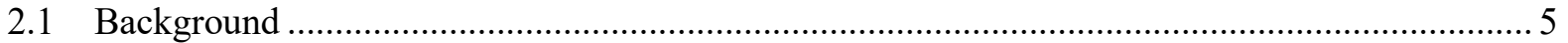

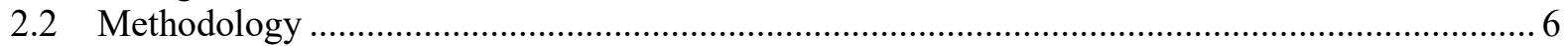

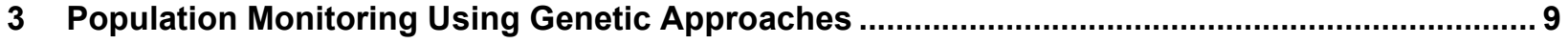

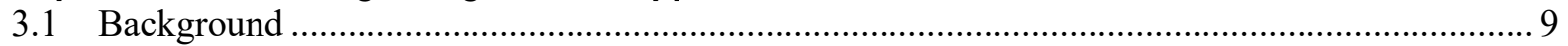

3.2 Population Genetic Techniques......................................................................... 10

3.3 Population Genetics Studies of Migratory Tree Bats ................................................ 12

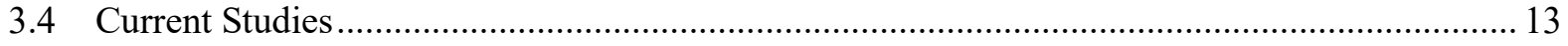

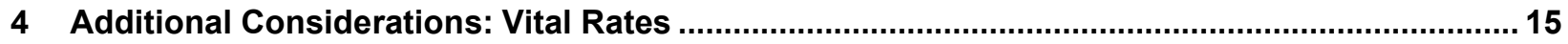

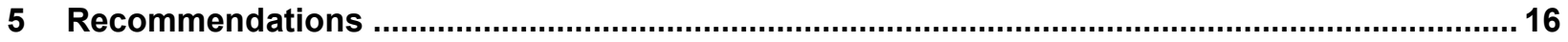

5.1 Acoustic Monitoring ....................................................................................... 16

5.2 Genetic Analyses......................................................................................... 19

5.2.1 Comparative studies ............................................................................. 19

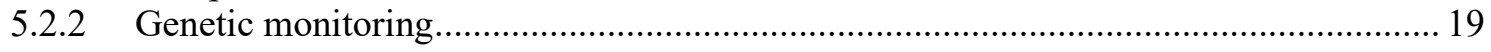

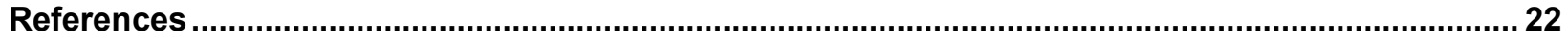

\section{List of Figures}

Figure 1. Species ranges and current wind energy deployment in the United States. Image credit, Billy Roberts, NREL

\section{List of Tables}

Table 1. North American Bat Monitoring Program Hubs and Contacts.... 


\section{Introduction}

Understanding the population structure (i.e., whether populations are panmictic or subdivided in some way) and dynamics (i.e., how populations change over time) of bats is essential for their proper management and sustainability. Knowing the size and trends of bat populations can assist in determining the extent and severity of an impact, and the efficacy of potential measures necessary for mitigation. Many bat species are exposed to both natural and human-induced environmental stressors including persecution, habitat loss, disease, human disturbance, and climate change (Jones et al. 2009; O'Shea et al. 2016; Frick et al. 2019). The apparent decline in bat populations across the globe is concerning. Bats have low reproductive potential (i.e., reproducing once per year with typically only one or two pups) and require high adult survivorship to avoid population declines (Barclay and Harder 2003; Podlutsky et al. 2005). Because bats are not able to recover quickly from population losses, broad scale increases in mortality may put populations at risk (Findley 1993; Henderson and Broders 2008).

In the United States, White-nose Syndrome (WNS) has decimated subterranean-hibernating bat populations, with some species experiencing declines greater than $90 \%$ (Turner et al. 2011; Langwig et al. 2012; Frick et al. 2015). Currently, 13 species are affected by WNS, including the little brown bat (Myotis lucifugus), a once common species, and the federally endangered Indiana bat (M. sodalis) (Frick et al. 2010; Thogmartin et al. 2013). It is relatively easy to quantify the impact of WNS on these species because they congregate in large numbers during winter and researchers have monitored caves and mines for decades tracking the trends in these populations over time (Cheng et al. forthcoming).

However, for tree-roosting species, such as hoary bats (Lasiurus cinereus), ${ }^{1}$ eastern red bats ( $L$. borealis), and silver-haired bats (Lasionycteris noctivagans), collecting and interpreting population data is more challenging (O'Shea and Bogan 2003). These species do not aggregate in conspicuous locations, but instead roost individually and are dispersed across the landscape making it impractical for traditional mark-recapture methods or other surveys to provide estimates of census population sizes (Carter et al. 2003). The current status of the hoary bat is "least concern" with population trend "unknown" by the IUCN Red List (Gonzalez et al. 2016), but several studies suggest that local populations may be declining based on decreases in capture rates (Morrell et al. 1999; Francl et al. 2012), the number of bats submitted for rabies testing (Whitaker et al. 2002), and acoustic activity patterns (Ford et al. 2011; Rodhouse et al. 2019). In 2017, the hoary bat was added to Appendix II of Convention on the Conservation of Migratory Species (www.cms.int). The current status of the eastern red bat is "least concern" with population trend "stable" by the International Union for the Conservation of Nature (IUCN) Red List (Arroya-Cabrales et al. 2016), although there is some evidence of regional declines based on decreases in capture rates (Winhold et al. 2008) and the numbers of bats submitted for rabies testing (Whitaker et al. 2002). In 2017, the eastern red bat was added to Appendix II of the Convention on the Conservation of Migratory Species (www.cms.int). The current status of the

\footnotetext{
${ }^{1}$ Recent phylogenetic analyses (Baird et al. 2015, 2017) suggest several taxonomic revisions, including the recognition of separate genera for hoary bats (Aeorestes), red bats (Lasiurus), and yellow bats (Dasypterus). We elected to use the traditional taxonomy, as it provides nomenclature stability and aids scientific communication (Novaes et al. 2018) and is currently recognized by the taxonomic nomenclature authority and database (www.batnames.org; Simmons and Cirranello 2020).
} 
silver-haired bat is "least concern" with population trend "stable" by the IUCN Red List (Solari 2019). Currently, there is no regulatory protection for these species in North America. In the United States, the U.S. Fish and Wildlife Service (USFWS) has developed a hoary bat focal species action plan to better understand the status of the species and how at risk it may be, to take proactive conservation actions to preclude any need to list the species under the Endangered Species Act. In Canada, the Committee on the Status of Endangered Wildlife in Canada has requested a status report in preparation for assessments for these three species by April 2022. ${ }^{2}$

The expansion of wind energy development, which is critical for reducing greenhouse gas emissions and mitigating the effects of climate change (Wiser et al. 2011), also represents a potential threat to the persistence of certain bat populations, as bats are killed at wind energy facilities worldwide (Arnett et al. 2016; O'Shea et al. 2016; Frick et al. 2017). In 2013, Arnett and Baerwald estimated that hundreds of thousands of bats are killed annually by wind turbines in the United States and Canada based on data from 1999 to 2011. Approximately $78 \%$ of reported fatalities across the two countries are from migratory tree-roosting species, including hoary bats (38\%), eastern red bats (22\%), and silver-haired bats (18\%) (Arnett and Baerwald 2013). At the time of the analysis, installed capacity was approximately $7.8 \mathrm{GW}$ and $47 \mathrm{GW}$ in in Canada and the United States, respectively (American Wind Energy Association 2013, Canadian Wind Energy Association 2020). By the end of 2019, installed capacity for both Canada and the United States more than doubled, with over $13 \mathrm{GW}$ and $105 \mathrm{GW}$, respectively (American Wind Energy Association 2020, Canadian Wind Energy Association 2020). Given continued growth of the industry, the wind energy and wildlife community is concerned about the potential population-level impact wind turbines may have on vulnerable bat species.

${ }^{2}$ http://www.cosewic.ca/index.php/en-ca/reports/status-reports-preparation 


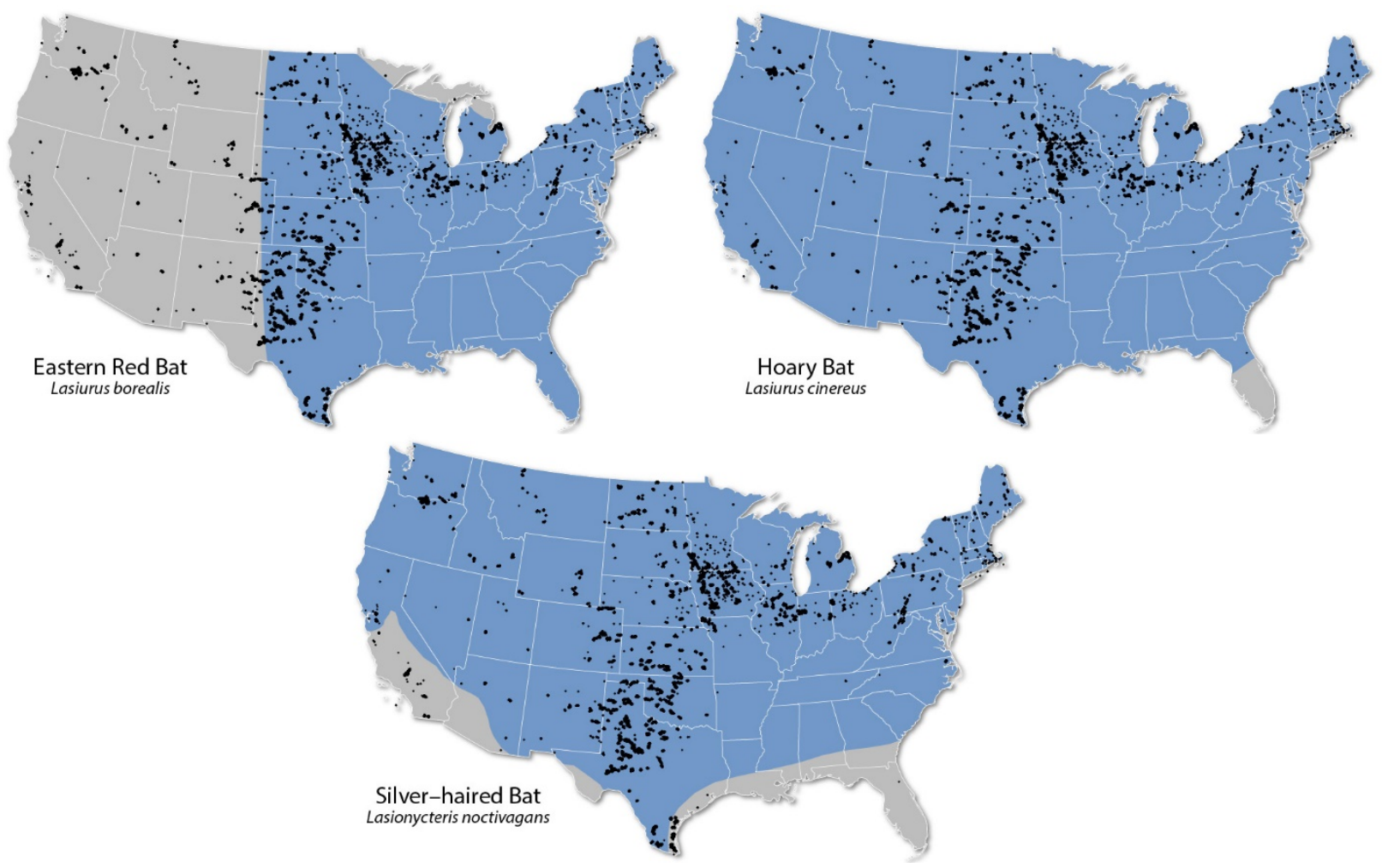

Figure 1. Species ranges and current wind energy deployment in the United States. Image credit, Billy Roberts, NREL

In response to the concern of wind turbine-related fatalities of bats, the American Wind Energy Association, Bat Conservation International, the National Renewable Energy Laboratory, and the USFWS formed the Bats and Wind Energy Cooperative (BWEC) in 2003

(www.batsandwind.org). One of the BWEC's initial priorities was to better understand bat populations to determine if fatality rates were sustainable. In 2018, the BWEC renewed the emphasis on addressing this priority. Also, in 2018, the conservation organizations Defenders of Wildlife and Bat Conservation International organized a group of wind energy and wildlife stakeholders to address the potential population-level impacts of wind turbines on hoary bats. The objective was to discuss measures the wind energy-wildlife community could take to better understand the population status and trends of hoary bats. Subsequent meetings were held in 2019, and the group decided to explore two approaches to population monitoring: acoustic surveys and genetic/genomic analyses. Empirical data from these efforts can be used to inform existing models to quantify the impact of wind turbines on hoary bats and assess and effectively minimize solutions that meet both conservation and renewable energy production goals.

To assess the magnitude of a stressor, quantifying mortality is only half of the equation. The other half is knowing the existing population size. For bats and wind energy development, we have incomplete data on both mortality and population size. Cumulative mortality estimates provide a relative magnitude of impact (i.e., hundreds of thousands of fatalities), but are biased (i.e., not representative of existing capacity nor randomly sampled). Current population estimates for migratory tree bats are derived from effective population data, but their usefulness is limited 
due to a lack of precision. For example, in lieu of empirical data for population size in hoary bats, Frick et al. (2017) employed expert elicitation to develop a model for the potential impact of wind energy on hoary bats. Holding both fatality rates and installed capacity static from 2014 data, and assuming a growth rate of $\lambda=1.01$ and a starting population of 2.25 million bats, the model indicated a $90 \%$ population decline in hoary bats by 2050 . Updated models, using the same assumption for growth rate, incorporated more realistic buildout and implementation of minimization strategies to the model developed by Frick et al. (2017) and suggested a 38\% reduction in turbine-related mortality would be necessary to manage extinction risk for a starting population of 2.25 million bats. For a starting population of 1 million bats, an $88 \%$ reduction in turbine-related mortality would be necessary (Electric Power Research Institute 2020). Improving these models requires additional data to fill in gaps and provide better precision. Although it may be impossible or impractical to get census data for most bat species, the combination of research findings from various research activities, such as systematic acoustic sampling and genomic analyses, will help reduce uncertainty and build a weight of evidence on the status and trends of bat populations. Using a weight of evidence approach is the most practical method to determine whether the magnitude of impact is of conservation concern and the level of minimization necessary to avoid population decline.

For tree roosting bats, there is a paucity of data on vital rates and population size, and it remains difficult to confidently assess population-level responses to sources of mortality (e.g., wind turbine collisions, disease, climate change, and/or habitat degradation). While the estimated annual mortality from wind turbine collisions has raised alarm, there is far too much uncertainty to know if and what level of response is necessary. Currently, there are no practical means to determine census population size, particularly in the near term; however, additional data can be collected to reduce uncertainty and assist in ascertaining population trends. This information is critical to understanding if and what level of minimization is necessary and appropriate for different stressors. Here, we synthesize the existing information related to bat population status and trends, uncertainty regarding existing estimates, current and novel methods for assessing population-level data, and recommendations for near-term and long-term studies to reduce uncertainty surrounding population data. Although this report focuses on wind energy development and bats, the methodologies used are broadly applicable and are being implemented by other industries, academia, government agencies, and nongovernmental organizations. Through efforts outside of the wind energy industry, it is likely we will gain a better understanding of bat populations, but the pace of data collection and analysis will be expedited by further participation by the wind energy industry. In return, the wind energy industry will benefit by contributing to these efforts either by 1) discovering that the population status of the species of interest is stable or growing, which may prevent the need for listing one or more species; or 2) recognizing the population status of certain species is in decline and implementing relatively moderate measures to reduce wind turbine-related mortality in the near term to stave off more stringent measures, which may be necessary if action is delayed. 


\section{Population Monitoring Using Acoustic Surveys}

\subsection{Background}

In April 2012, the Conservation and Recovery Working Group of the White-nose Syndrome National Plan convened "A Workshop on Bat Population Monitoring and Modeling" to begin the process of developing plans for monitoring and modeling population trends for bats (Loeb et al. 2012). The intent was to build on the outcomes and recommendations from O'Shea and Bogan (2003). The goals of the workshop were to: 1) convene bat researchers, population modelers, statisticians, and experts in the field of wildlife population monitoring to design statistically robust and logistically feasible methods for monitoring changes in bat populations; and 2) determine areas of overlap with existing monitoring and modeling efforts to ensure efficiency and consistency.

At the 2012 workshop, five different sampling methods were developed for different species or scenarios (i.e., colony counts for subterranean-roosting species). Consensus was reached that acoustic monitoring (i.e., a combination of acoustic driving transects and acoustic point monitoring) for solitary-roosting species should form the basis of a statistically rigorous sampling framework monitoring program because of the relatively low cost of acoustic monitoring and the ability to simultaneously survey for multiple species at one location (Loeb et al. 2012). The workshop spurred the development of the North American Bat Monitoring Program (NABat), which is a multiagency, multinational effort designed to address the lack of standardized monitoring for bat species across North America (Loeb et al. 2015). The purpose of NABat is to create a collaborative continentwide program to monitor bat presences and distribution from local to rangewide scales that will provide reliable data to promote effective conservation decision-making and the long-term viability of bat populations across the continent (Reichert et al. 2021). To achieve this, several objectives were identified, including:

1. Define a statistically robust continentwide sampling framework

2. Provide recommended field protocols for acoustic monitoring data collection

3. Develop data standards and a central repository ${ }^{3}$ for acoustic, winter and summer colony counts, and emergence and capture data

4. Provide statistical analyses of status and trends in populations at national and regional scales.

NABat systematically identifies priority cells from which to collect data and uses probabilitybased sampling, which is widely recognized as being important for environmental monitoring where valid statistical inference from a sample to a population of interest is desired (Cochran 1977; Green 1979; Olsen et al. 1999; Thompson 2002; Gitzen et al. 2012). This is particularly critical for bat monitoring because of the inherent difficulties in describing the status and trends of bat populations (Hayes et al. 2009; Rodhouse et al. 2011; see Loeb et al. 2015, Ch. 3 for details on the sampling design for NABat).

\footnotetext{
${ }^{3}$ https://sciencebase.usgs.gov/nabat/\#/home
} 


\subsection{Methodology}

NABat uses a master sample approach (Larsen et al. 2008) with a grid-based framework of $10 \mathrm{x}$ $10 \mathrm{~km}$ grid cells across North America. A generalized random-tessellation stratified survey design algorithm (Stevens and Olsen 2004) assigns a spatially balanced and randomized ordering of the $100 \mathrm{~km}^{2}$ cells, which are considered the priority cells for sampling (Loeb et al. 2015). Monitoring within this standardized framework allows statistical inference to nonsurveyed locations and ensures the validity of analyses at regional and rangewide scales (www.nabatmonitoring.org/about-1).

Mobile transects are designed to sample high spatial, temporal, and inter-specific variation in habitat use by sampling diverse habitats over large areas with few resources (Roche et al. 2005). They are most applicable in areas where roads are easily accessible and safely driven at a speed of $32 \mathrm{~km} / \mathrm{h}$ (20 mph). For NABat, mobile transects occur for 1 to 2 hours each night; each transect should be surveyed on two nights within the same week, and transects should be 25 to $48 \mathrm{~km}$ in length (see Loeb et al. 2015, Ch. 5).

Using this approach assumes that each bat pass represents a distinct individual because the rate the vehicle is moving is faster than the bats flying (i.e., most bats in the United States and Canada fly between 9 and $32 \mathrm{~km} / \mathrm{h}$ ), and it is unlikely to encounter the same bat twice (Grodzinski et al. 2009; Hayward and Davis 1964; Kennedy and Best 1972; Patterson and Hardin 1969; Schaub and Schnitzler 2007). For mobile transects, the response variables are detection/nondetection of each species and the number of bat passes per species along the transect. Thus, the number of passes can be used as an index of relative abundance (Roche et al. 2011) to estimate changes in populations over space or time. Species-level biases associated with their affinities for or avoidance of roads or roadside habitat are still possible, but extending transects, increasing the number of transects, incorporating temporal and spatial variability may help reduce potential biases (Roche et al. 2011; Whitby et al. 2014).

Stationary surveys can be used if roads are limited (see Loeb et al. 2015, Ch 4). Moreover, stationary surveys, if randomly selected, remove the potential road bias and can control for factors that may affect call quality and quantity. However, stationary surveys cannot provide reliable estimates of abundance or density because it is not possible to relate the number of calls detected to the number of bats present based on the number of passes. For NABat, each recorder is deployed for four nights. The recommended sampling intensity is four detectors per 10-km-by$10-\mathrm{km}$ grid cell. Ideally, one detector is placed in each of the four $5-\mathrm{km}-\mathrm{by}-5-\mathrm{km}$ quadrants to minimize spatial autocorrelation. For stationary surveys, detection/nondetection is the response variable, which can be used to assess trends in site occupancy and habitat use over time.

The primary analytical goal of NABat is to provide inferences regarding the distribution and relative abundance of bats (Loeb et al. 2015, Ch. 9). Occupancy models can be used to estimate changes in species distribution over time. Estimation of occupancy requires replicate sampling at selected sites (or grid cells). The number of sites and years required to assess population trends will vary based on the area of interest (e.g., state, region, country), and commonality of the species (i.e., the duration of sampling will be shorter for more common species). For example, Rodhouse et al. (2012) achieved a sample size of 50 to 70 cells for each year of a study across Oregon and Washington and detected spatio-temporal variations over 4 years for common species. A power analysis may be necessary to guide specific study designs intent on detecting a 
given amount of population change (Banner et al. 2019). For example, in their simulations Roche et al. (2011) reported a 50\% decline for the common pipistrelle should be detectable within 8 years, but it would take up to 15 years to detect a $25 \%$ decline.

Detection histories are used in an occupancy modeling framework to estimate the probability that a species occurs within a 10-km-by-10-km grid cell over the period when surveys were conducted (i.e., early summer for NABat). There are at least two major benefits for using occupancy models to understand status and trends of bats from acoustic monitoring data. First, occupancy models allow one to explicitly estimate and then account for imperfect detection (false negatives) of bats from acoustic monitoring data. Acoustic monitoring is not perfect. Bats passing by an acoustic detector are not always recorded, and if they are, their echolocations are not always classified to the correct species. Using occupancy models, one can estimate the probability of detecting a species given the species occurred within a 10-km-by-10-km grid cell. Information on the estimated probability of detection is then used to more accurately estimate the probability that a species occurs within a grid cell. Neece et al. (2019) demonstrated that NABat surveys are feasible for large-scale monitoring, but they reported higher detection probabilities for stationary points relative to mobile transects. They therefore recommended using a combination of both approaches with each $10-\mathrm{km}-\mathrm{by}-10-\mathrm{km}$ priority cell.

The second major benefit of using occupancy models for understanding status and trends from acoustic monitoring data is that occupancy models can be used to easily predict the occurrence of species in areas where sampling did not occur. Predictions of nonsampled NABat grid cells are based on modeled relationships between detection-nondetection data and the underlying environmental covariates (e.g., distance to water, percent forest cover) driving a species' distribution. Estimated species occurrence across any subset of NABat grid cells (e.g., state, region) can be easily displayed as species distribution maps, used to quantify associations between species occurrence and biologically meaningful covariates, and used to predict the consequences of changes in covariates on species' distributions or species occupancy. There are several guidance documents for NABat to assist users in creating an NABat project, establishing grid cells, and processing data. ${ }^{4}$

Multiyear information from repeated annual surveys permits the extension of the model to estimate parameters associated with changes in occupancy dynamics, including colonization rates and local extinction, defined as the probability of a site being unoccupied in 1 year given it was occupied the previous year (MacKenzie et al. 2006). For example, Rodhouse et al. (2019) assessed occupancy data collected between 2003 and 2010 and updated with new data from 2016 to 2018 in Oregon and Washington. Using a multiseason occupancy model, they observed a regionwide summertime decline for hoary bats, but no evidence of decline for little brown bats. Despite the relatively large geographic scope, it only included about $5 \%$ of the area of the continental United States and was regionally focused, so conclusions about population status of the two species at larger spatial scales could not be drawn. Rodhouse et al. (2019) suggested that the solution was to conduct a broader regional and rangewide replication of coordinated monitoring. The authors conclude by stating that empirically informed Bayesian modeling, fueled by large monitoring datasets that accumulate over time and that are underpinned by a

${ }^{4}$ https://www.nabatmonitoring.org/resources 
robust survey design, such as NABat, provides a powerful and flexible foundation for building an adaptive, evidence-based conservation information system.

Two barriers to NABat adoption are technology and labor costs, and data management. With respect to technology, acoustic detectors can be expensive, with each detector costing $\$ 1,000$ $\$ 2,000$ (not including costs associated with the equipment, such as weather proofing, data cards, etc.). Therefore, sampling one $100-\mathrm{km}^{2}$ cell using four detectors can cost $\$ 4,000-\$ 8,000$, before accounting for labor and data management time. Many research entities already have the equipment, but may need to update some accessories (e.g., microphones), thus minimizing the equipment costs. However, currently deployed detectors may not readily save metadata of importance. Data management may pose a greater barrier than equipment cost and deployment. Compiling, processing (to identify species), organizing, and uploading data to the NABat database can be onerous and labor intensive, particularly for new users. Users must adopt the NABat protocol and submit their data to the database, both of which are critical to the success of the continental program given that the full value can be realized only through the pooling of common data across the continent.

The U.S. Geological Survey NABat Coordinating Office is currently working to address these barriers in two ways. First, it is building tools, creating guidance documents, and training users to support implementation. This includes maintaining and expanding front-end web applications, back-end databases, and tools to improve data submission and access. In addition, NABat created the NABat National Data Processing Laboratory in partnership with Bat Conservation International to develop more efficient data processing and management workflows and systems to resolve challenges associated with high-volume acoustic data processing and management. This approach allows data contributors to focus on data collection, rather than data management and processing. Second, the NABat Coordinating Office is working to establish regional NABat Hubs to coordinate data collection, equipment sharing, and data management and submission within each region. Through effective implementation across the continent, NABat is building capacity to support local to rangewide analyses that can inform responses to WNS, inform Endangered Species Act prelisting and recovery actions, and improve understanding on the impacts of wind energy on bats. 


\section{Population Monitoring Using Genetic Approaches}

\subsection{Background}

Trying to understand and quantify the impacts of wind energy on bats is difficult in and of itself (i.e., without estimates of census population sizes, $\mathrm{N}_{\mathrm{c}}$ ), but the background against which we are attempting to do so can make the task seem almost insurmountable. While migratory treeroosting bats are undoubtedly experiencing a new source of mortality because of wind energy, they are simultaneously experiencing climate change impacts (Sherwin et al. 2013; Frick et al. 2019); global declines in insects (Hallman et al. 2017; Sánchez-Bayo \& Wyckhuys 2019), which are the primary food source for migratory tree-bats; and continued habitat loss and degradation (Frick et al. 2019), among other stressors. Furthermore, there is evidence that genetic diversity is also already decreasing in a measurable way in natural populations; a recent analysis by Leigh et al. (2019), for example, shows a $6.5 \%$ decrease in allelic diversity and a $5.4 \%$ decrease in expected heterozygosity (two parameters that are commonly estimated in population genetics) in wildlife populations from which both historical and contemporary genetic samples were available for analysis across an average of 110 years.

Nonetheless, if we capitalize on both the recent advances in the tools and analytical approaches to monitor genetic variation in wildlife populations, and the large quantity of bat carcasses that are recovered from distinct geographic locations at particular times of years across the United States (i.e., during postconstruction fatality surveys at wind energy facilities), we can make tremendous progress answering questions related to population status and trends, geographic ranges, seasonal movements, and cryptic species (i.e., species that appear to be morphologically indistinguishable but that are genetically distinct and do not interbreed) - all aspects of bat biology that require additional investigation. Furthermore, we can use genetic monitoring over time to capture changes in genetic diversity that reflect changes in population size due to wind turbine mortality as well as other stressors that are simultaneously impacting bat populations. Although it is not possible to isolate changes in genetic diversity due to wind energy impacts from other impacts like climate change, the magnitude and scope of these cumulative changes can be used to guide management and mitigation decisions that will be important for the overall conservation of migratory tree bats.

Genetic variation is fundamental to population fitness and adaptation to environmental change, and it is widely recognized that loss of genetic diversity impedes long-term survival of species (Frankham et al. 2009). When formerly large populations are reduced to small sizes, standing levels of genetic diversity decline and natural selection acts less effectively on both advantageous and deleterious alleles. Inbreeding commonly increases as well, exposing deleterious recessive variants that reduce mean population fitness (Frankham et al. 2009; Koepfli \& Gooley 2020). Therefore, understanding the amount of genetic diversity contained in wild populations and how it is distributed among geographic populations is a major concern for conserving the integrity and sustainability of species. From a practical point of view, many important insights gleaned from molecular genetic data have direct relevance to the design and implementation of conservation management strategies. For example, a recent study using a population genomics approach to quantify the impacts of roads on population fragmentation in eastern tiger salamanders (Ambystoma tigrinum) found high levels of genetic divergence among 
ponds and concluded that these endangered amphibians would require management at the individual pond, or pond cluster, level (McCartney-Melstad et al. 2018).

Population genetic approaches have the potential to reduce uncertainty regarding the impacts of wind energy on migratory tree bat populations. In addition to estimating genetic diversity, population genetic analyses can estimate current and historical effective population sizes, detect population bottlenecks, and identify evolutionarily unique subpopulations (Frankham et al. 2009). The effective population size $\left(\mathrm{N}_{\mathrm{e}}\right)$ is the size of an abstract population with random pairing of gametes and discrete generations that would experience the same amount of genetic drift (loss of genetic variation due to chance) as the observed population of interest. $\mathrm{N}_{\mathrm{e}}$ is on average $11 \%$ (range: $5 \%-80 \%$ ) of the census population size $\left(\mathrm{N}_{\mathrm{c}}\right)$ across unmanaged animal populations, as just about anything that increases the variance among individuals in reproductive success (e.g., nonrandom mating) will reduce $\mathrm{N}_{\mathrm{e}}$ (reviewed in Frankham 1995). $\mathrm{N}_{\mathrm{e}}$ is particularly sensitive to variance in family size, unequal numbers of males and females, and to population size fluctuations (Frankham 1995). For a species that loses genetic variation to drift (i.e., because of a severe bottleneck), the accumulation of new genetic variation will take place slowly, at the underlying mutation rate, and estimates of $\mathrm{N}_{\mathrm{e}}$ will tend to stay low because $\mathrm{N}_{\mathrm{e}}$ is most sensitive to the smallest census population sizes over time. When formerly large populations decrease in size, genetic diversity decreases in predictable ways. Therefore, even in the absence of census population size estimates, repeated genetic monitoring over time can reveal changes in $\mathrm{N}_{\mathrm{e}}$ that show the population is either increasing or decreasing in size (Schwartz et al. 2007) and provide insights with direct implications for management. For example, genetic monitoring of an endangered population of Atlantic salmon (Salmo salar) from Maine revealed significant decreases in $\mathrm{N}_{\mathrm{e}}$ and several measures of genetic diversity from 1963 to 2001 (Lage and Kornfield 2006). This finding, in conjunction with reduced counts of adult salmon returning to the river to spawn, suggests that current restoration efforts may be negatively impacted by this historical loss of diversity (Lage and Kornfield 2006).

Genetic diversity and population structure of impacted bat species likely affect resiliency to sustained wind turbine mortality and the likelihood of population persistence. For example, species with smaller effective population sizes $\left(\mathrm{N}_{\mathrm{e}}\right)$ contain lower levels of genetic diversity that may limit their evolutionary potential to respond to selection and avoid inbreeding in the future (Frankham et al. 2009). Although it is unlikely that migratory tree bats will be impacted by inbreeding in the short term, we can monitor $\mathrm{N}_{\mathrm{e}}$ and other measures of genetic diversity to determine if these species are currently losing genetic variation that could be related to future adaptation.

\subsection{Population Genetic Techniques}

There are several tools available to characterize and monitor genetic variation in populations, and numerous review papers and texts illustrate how these data have been applied to the conservation of natural populations (e.g., Avise 2000; Frankham et al. 2009; Allendorf 2017; Ortega and Maldonado 2020). Measures of genetic diversity were originally based on a relatively small sampling of polymorphic loci defined by protein structural variants (allozymes), which provided the first estimates of the amount of genetic variation within and between natural populations in the 1970s (Selander 1976). The next breakthrough was the description of genetic variation in mitochondrial DNA (mtDNA) using differences in the location of restriction enzyme cutting 
sites (Avise et al. 1979; Brown \& Wright 1979). Whereas allozymes have a biparental pattern of inheritance, mtDNA is passed almost exclusively from mother to offspring without recombination, thereby providing a different perspective of the genetic structure of natural populations. The next innovation was the application of restriction fragment length polymorphisms to analyze repetitive patterns of nuclear DNA to produce genetic fingerprints that were unique to each individual (Jeffreys et al. 1985), followed by development of microsatellites in the late 1990s (Goldstein \& Pollock 1997). Microsatellites reflect variation in the number of short tandem repeats ( $2-5$ base pairs in length) at loci throughout the genome, are highly variable, and rely on the polymerase chain reaction to amplify the DNA. Genotyping many microsatellite loci makes it possible to identify individuals, assign paternity and maternity, estimate kinship, identify the geographic origin of individuals, detect dispersal, detect genetic bottlenecks, estimate effective population size, and describe genetic patterns and spatial structure within and among populations.

The most recent innovation in detecting genetic variation in natural populations has been the high-throughput application of single nucleotide polymorphisms or SNPs (Morin et al. 2004). SNP variation in aggregate is more abundant in the genome and far more tractable to model than microsatellite variation, and has greatly improved power to estimate genetic diversity, effective population size, gene flow, and other population demographic parameters important for conservation (Allendorf et al. 2010; Ellegren 2014). In recent years, SNPs have been used increasingly to characterize genetic variation in natural populations (Supple and Shapiro 2018). The advent of next-generation sequencing methods such as restriction-site associated DNA sequencing (RADseq) that provides hundreds or thousands of SNPs across the genome or even low-coverage whole genome sequencing has now made this possible (Forcina and Leonard 2020).

The transition from studies using 10-20 microsatellite loci and several hundred base pairs of mtDNA sequence data to those using hundreds or thousands of SNPs, has led a change in thinking - from a population genetics perspective to a population genomics perspective (Allendorf 2010). Although this difference was initially perceived as a difference in the number of markers that could be analyzed, it quickly became apparent that this revolution in techniques and analytical approaches would lead to new questions about the evolutionary processes that influence variation within genomes themselves as well as new research opportunities (Luikart et al. 2003; Hohenlohe et al. 2010). A crucial component of all genomic techniques is bioinformatics, and the tools for processing large amounts of genomic data are changing fast (Allendorf et al. 2010; Pevsner 2015). Researchers using genomic techniques should plan on a substantial investment of time and resources devoted to data storage and analysis.

Despite the advances in genomics techniques, microsatellite loci and mtDNA sequences remain important and cost-effective markers for analyses of genetic diversity, kinship, inbreeding status, and population structure in many mammal species, especially for those that are being analyzed for the first time (Koepfli and Gooley 2020). These markers are often assumed to be neutral with respect to selection and therefore provide unbiased estimates of random processes such as genetic drift. The increasing accessibility and application of genomic and high-throughput sequencing approaches now makes it possible to generate enormous amounts of data at high resolution to better quantify the extent and patterns of genomewide genetic diversity (e.g., 
Dobrynin et al. 2015; reviewed in Allendorf et al. 2017), including adaptive variation that is subject to selection (Kirk and Freeland 2011).

Genomics resources, including the generation of de novo reference genome assemblies, are being produced by individual investigators as well as by international genome consortia such as the Genome 10K Project (Koepfli et al. 2015). For bats, the Bat 1K consortium, is working toward the goal of generating chromosome-level genomes for all 1,300 living bat species (Teeling et al. 2018); that will have widespread impacts on a range of diverse scientific fields including disease, communication, aging, and molecular evolution. It is envisioned that this enhanced view of genetic diversity within and among bats will, for example, improve our understanding of the molecular basis of adaptations and evolutionary history and aid in the conservation of bats (Teeling et al. 2018). Once a reference genome is generated and additional individuals are whole genome re-sequenced and mapped to the reference, it is possible to extract thousands to millions of SNPs that can be used to genotype samples from natural populations. Genomic studies are revealing the importance of ancient and recent interspecific hybridization; they empower greater delimitation of cryptic species, evolutionary significant units, and subspecies (Coates et al. 2018), and will likely change how populations are studied and managed (Supple and Shapiro 2018).

\subsection{Population Genetics Studies of Migratory Tree Bats}

Several recent studies have used population genetic approaches to elucidate patterns of genetic variation, identify potential barriers to gene flow, and estimate $\mathrm{N}_{\mathrm{e}}$ for three migratory treeroosting bats. For the eastern red bat, several studies estimating $\mathrm{N}_{\mathrm{e}}$ have come to similar conclusions that the effective population size is in the hundreds of thousands to millions of individuals, with no evidence of barriers to gene flow among groups of samples (Korstian et al. 2015; Vonhof and Russell 2015; Pylant et al. 2016; Sovic et al. 2016). For eastern red bats killed at wind energy facilities in the central Appalachian Mountains of the United States, Pylant et al. (2016) found a large $\mathrm{N}_{\mathrm{e}}$ reflecting a demographic expansion after a bottleneck with no evidence of population genetic structure. Similarly, Vonhof and Russell (2015) analyzed a data set of eastern red bats collected primarily in the eastern portion of their range and found no evidence for historical use of different migratory pathways and no evidence for barriers to gene flow among their sampling localities. Furthermore, estimates of $\mathrm{N}_{\mathrm{e}}$ from this study were in the hundreds of thousands to millions of individuals from what the authors described as a single, panmictic population. A recent study by Ammerman et al. (2019) report a high level of multiple paternity in eastern red bats: $71 \%$ of parent/offspring groups consisted of half siblings and this is the highest level of multiple paternity reported for any bat species to date. Multiple paternity can increase $\mathrm{N}_{\mathrm{e}}$ if it lowers variance in male reproductive success and may be an adaptive strategy to allow for increased genetic variation and relatively large litter size (Sugg and Chesser 1994; Pearse and Anderson 2009; Gregory et al. 2012). These attributes might make eastern red bats somewhat more resilient to population declines due to wind turbine mortality compared to hoary bats. Similarly, there is no evidence of population genetic structure in the hoary bat (Korstian et al. 2015; Pylant et al. 2016; Sovic et al. 2016), although the estimates of $\mathrm{N}_{\mathrm{e}}$ are smaller for this species (ranging from several thousand to hundreds of thousands of individuals) compared to the eastern red bat and suggestive of either a stable or declining population (Pylant et al. 2016). Sovic et al. (2016) also analyzed genetic samples from silver-haired bats (using next-generation sequencing with 1,000 s of loci), and they came to similar conclusions - there is no evidence for 
population structure in this species, although it had the smallest estimated $\mathrm{N}_{\mathrm{e}}$ of the three migratory tree bats (current $\mathrm{N}_{\mathrm{e}}$ in silver-haired bats: 155,364 to 231,689; current $\mathrm{Ne}$ in hoary bats: 730,470 to 884,046 ; current $\mathrm{N}_{\mathrm{e}}$ in eastern red bats: $1,241,280$ to $1,692,254$ ).

It is important to note, however, that the high levels of gene flow and population connectivity observed within these North American migratory tree bats are based on studies with limited geographic scope (i.e., only a portion of the species' geographic range). We do not yet know if these high levels of gene flow and population connectivity will also be observed across the entirety of their respective geographic ranges. Future monitoring and management efforts must integrate information from across their entire ranges, as the potential impacts of mortality in any given region may have far-reaching implications. Although there is currently no strong genetic evidence of population declines in these species, data from other sources suggest their populations may be declining and are at risk. Korstian et al. (2015) cautioned that genetic monitoring of migratory tree bats specifically for detecting population declines caused by wind turbines may be impractical using a limited number of genetic loci due to the large effective population sizes and high levels of gene flow in these species. Instead, they suggested that future efforts should focus on developing genomic resources for these species, obtaining better estimates of mutation rates, and conducting rangewide population genetic studies to better estimate historical and current population sizes.

\subsection{Current Studies}

With respect to migratory tree bats and wind energy, the application of a genomics approach with large SNP datasets can reduce some of the uncertainty regarding population status and trends for these species and guide the implementation of mitigation efforts when and where deemed necessary. For example, by increasing the number of markers, genomics will provide greater power to estimate and monitor $\mathrm{N}_{\mathrm{e}}$, identify population bottlenecks, and improve identification of evolutionarily significant units and management units, and may provide additional power to detect more subtle patterns of differentiation and estimate demographic patterns and/or parameters with greater precision (Allendorf et al. 2010).

One current project is using RADseq techniques to examine genetic variation in hoary bats collected at two points in time from a single geographic location (unpublished U.S. Geological Survey-Fort Collins Science Center and the USFWS). One sample consists of 96 hoary bats collected at wind turbines from 2009 to 2010, whereas the second sample consists of 96 hoary bats collected from 2017 to 2018 from wind turbines in the same geographic region as the first sample. The sample size of 96 in each temporal replicate is deemed to be sufficiently large to meet the study objectives and reflects the technology that is used in RADseq techniques; i.e., analyzing samples using 96-well plates is convenient and a cost-effective use of resources. Using data from $\geq 10,000$ SNPs, the research team is characterizing genetic variation, looking for evidence of population substructure, and estimating $\mathrm{N}_{\mathrm{e}}$ at both points in time. Given that it is difficult to estimate variance in $\mathrm{N}_{\mathrm{e}}$, it may not be possible to determine if $\mathrm{N}_{\mathrm{e}}$ is increasing, decreasing, or remaining stable over a single 8- or 9-year period. This could mean that additional sampling of more cohorts over space and time will be needed to better understand variance in $\mathrm{N}_{\mathrm{e}}$ and allow for analysis of population trends over time. Nonetheless, this project is the first to apply this approach using repeated sampling of migratory tree bats over time, and the lessons learned here will be used to inform future monitoring efforts. Published results are expected in 
spring 2021. The research team has published the hoary bat genome ${ }^{5}$, which scientists at the Baylor College of Medicine have already used to create an even more complete genome sequence $^{6}$ (i.e., gapless full-chromosome sequences), which will further expand the tools available to investigate hoary bat genomics.

A second research team (University of Maryland Center for Environmental Science) is currently using next-generation sequencing technology to characterize genetic diversity and effective population sizes, and to look for evidence of population structure for these three species of migratory tree bats. The goal of this project is to collect samples from across the entire range of each species, which differs from previous research in which the data collected were more localized (e.g., Pylant et al. 2016). Results will be available in the next year or two.

Finally, although not using a genomics approach, a third study is in progress (Texas Christian University) with the goal of examining patterns of genetic diversity in two species of yellow bat - the northern yellow bat (Lasiurus intermedius) and the southern yellow bat (Lasiurus ega) - that are experiencing wind turbine mortality in south Texas. Yellow bats are closely related to hoary and red bats, and the potential for collision mortality with wind turbines is high given their shared evolutionary history with these species. Wind energy is also a new source of mortality for yellow bats, and Chipps et al. (2020a) recently reported a significant female bias in collision mortality (based on molecular sex determination) for the southern yellow bat. Estimates of historic effective population size and diversity in both yellow bat species are lower than those reported in the other tree bat species studied to date (using similar methods; Chipps 2020b). The genetic diversity study therefore has the potential to provide additional insights into their basic life history while also providing genetic data to be used in future genetic monitoring of these species. Results from this study have been submitted for peer review and will be available by 2021. This study also demonstrates the utility of continuing to use lower cost methods such as microsatellites and mtDNA sequence data to investigate genetic variation in new species of interest for which genomics tools are not yet available (Koepfli and Gooley 2020).

${ }^{5}$ https://www.ncbi.nlm.nih.gov/assembly/GCA_011751065.1

${ }^{6}$ https://www.dnazoo.org/assemblies/Aeorestes_cinereus 


\section{Additional Considerations: Vital Rates}

In 2012, the Conservation and Recovery Working Group of the White-nose Syndrome National Plan discussed the importance of monitoring and modeling demographic parameters such as survivorship and reproductive parameters (Loeb et al. 2012). Understanding these parameters will 1) help determine whether bat population numbers are changing, 2) will allow assessment of population vulnerability over time, 3) serve as an alternative to estimating population size, 4) predict the probability of extinction, and 5) assess the ability of bats to recover from declines (O’Donnell 2009; Frick et al. 2010).

Demographic studies are useful for understanding the importance of survival, movement, and reproductive rates on population growth, and for predicting potential extinction risk of species given a stressor (Erickson et al. 2014). Because vital rates are lacking for most migratory tree bat species, including hoary bats, Frick et al. (2017) used 14 empirical studies on demography of 9 vespertilionid bats, of which the genus Lasiurus belongs, (Lentini et al. 2015; O'Shea et al. 2004) and compared the rates to those included in their expert elicitation. The median values of population growth rate for the published literature of closely related species and expert elicitations were 1.0025 and 1.015 (or growth rates of 0.25 to $1.5 \%$ ), respectively. These suggest that modest population growth rates seem sufficient for populations in the absence of wind energy, but are too low to sustain populations given the observed level of annual mortality (i.e., estimated as hundreds of thousands of bats per year in the United States and Canada; Arnett and Baerwald 2013) caused by wind turbines. Given that 6 of the 8 experts estimated the hoary bat population to be at or below 2.5 million individuals, if hoary bats have growth rate of 1.01 (1\%) — which would otherwise allow for slightly increasing populations - fatalities from wind facilities, if additive, would result in a $90 \%$ decline in the hoary bat population in 50 years if wind turbine fatalities were held constant at 2014 levels (Frick et al. 2017).

The lack of demographic information for species like hoary bats highlights the need to collect data necessary to determine vital rates. However, these efforts are challenging and studies may require $\geq 5$ years of data on marked individuals (O'Donnell 2009). Tree-roosting bats are difficult to track over time because they do not aggregate in colonies. Individuals must be captured and identified, but long-term marking techniques are problematic, and mist-netting is labor intensive and expensive. Although these data are necessary to determine population growth rates and fit models relating the impacts of a stressor on a population (Frick et al. 2017; EPRI 2020), collecting the data remains logistically challenging and expensive. However, integrated population models and modeling packages such as the BatTool (Erickson et al. 2014) could provide a basis for exploring how to integrate data sources from NABat to general demographic models to improve inferences. Moreover, the models used by Frick et al. (2017) and the Electric Power Research Institute (EPRI; 2020) may be more sensitive to population size than growth rate, suggesting that it is critically important to assess the current population size of hoary bats and evaluate trends over time. 


\section{Recommendations}

Population size, growth rates, and demographic data provide basic ecological information necessary to understand the health of populations. However, these data remain elusive for most bat species, particularly for migratory tree-roosting bats. These species can be difficult to capture and track over time, research can take years before enough data are collected to assess population trends, and data collection and analysis can be costly. Yet, without these data, it is difficult to determine whether a given impact, or a combination of impacts, is having a population-level effect on any species. With respect to wind energy development and migratory tree bats, quantifying the population size will help stakeholders understand whether the mortality associated with wind turbines is sustainable, the level of mitigation potentially required, and whether mitigation measures are effective in ensuring the stability of populations. In the absence of more precise population size estimates, population trend data can still be useful and inform stakeholders whether mitigation is necessary to sustain a species.

Currently, no single method can provide a precise population estimate for hoary bats or other migratory tree-roosting species. Thus, we must use a weight-of-evidence approach to better understand the viability of the species. Multiple lines of evidence, even if indirect, will be required to assess the status of bat populations (Rodhouse et al. 2019).

Consistent, long-term data collection remains the most reasonable option for reducing uncertainty and offering visibility into population trends for migratory tree-roosting bats. Statistically robust methods for collecting acoustic data, as detailed in NABat protocols, or estimating effective population size at repeated intervals and examining evidence for genetic bottlenecks will provide data points over time to show species trends. Unfortunately, there are no options for short-term actions that will result in significantly reducing uncertainty. However, there is opportunity for relatively short-term investments that can support long-term success of data collection efforts. These include modifying the way we collect and analyze acoustic data for bat surveys associated with wind energy development, supporting the establishment of a continental-scale NABat hub network and comprehensively analyzing currently available genetic material.

\subsection{Acoustic Monitoring}

Standard preconstruction acoustic surveys can provide valuable information on bat activity patterns and species occurrence at a proposed project. However, one of the main objectives for preconstruction acoustic surveys has been to assess whether preconstruction activity predicts postconstruction mortality. To date, no reliable relationship has been established (Solick et al. 2020; Richardson et al. 2021). There are ways to improve preconstruction acoustic data collection and analysis (the discussion of which is out of scope for this paper), which may help determine whether it can predict risk. Regardless, standard preconstruction acoustic surveys may be preferred or required for a project. If so, the data can still be submitted to NABat. Subsets of preconstruction acoustic monitoring data could be submitted in compliance with NABat data standards. Alternatively, multiseason or year-round preconstruction data from multiple sites would contribute to analyses looking at seasonal relationships and the full annual cycle for species, which we lack winter data (i.e., species that do not aggregate in winter hibernacula). 
Alternatively, the resources used for standard preconstruction acoustic monitoring can be used to follow the NABat field methods and data submission protocols or support the establishment of an NABat regional hub network. Contributing to NABat will enable broad-scale inferences about bat populations. This approach has several additional benefits in that the data are not necessarily associated with a given wind energy project and the level of effort/cost, even for multiple years of data collection, may be equivalent to standard preconstruction acoustic surveys conducted in 1 year at a single wind energy project.

To date, the NABat program has established five regional hubs, representing 21 states plus Washington, D.C., to help coordinate data collection and analysis (Table 1). Hubs are regional collaboratives that serve as nodes in the broader network, working to implement NABat locally and contribute to local- to continental-scale objectives. Led by a funded regional coordinator, hubs leverage resources and expertise across organizations to provide services, overcome challenges, optimize monitoring efforts, and fill information needs while populating the central NABat database. Partners in regional hubs include tribes, federal agencies, state or provincial agencies, academia, consultants, and nongovernmental organizations. Given that the wind industry is a relevant stakeholder, it would be highly beneficial for industry to be represented in these regional collaborative efforts.

Data from these regional hubs will be incorporated into the continental program while also supporting region-specific research objectives. The coordinator of each hub is responsible for securing sustainable funding through federal, state, and private contributions. Near-term investments in NABat could increase the speed and stability in which a complete network of regional hubs are established, can begin contributing to the continental program, and meeting region-specific needs. In 2021, the NABat Coordinating Office will begin publishing annual status and trends for species which data holdings are sufficient for analysis, including hoary bats, silver-haired bats, and eastern red bats. Support and data from acoustic or capture studies conducted by wind developers will increase the quantity and quality of data available for such reports, offering in return data-driven updates to species range maps, probability of occupancy at a $10-\mathrm{km}$ resolution, indices of abundance, and improved understanding of relationships to landscape features, resources, and multiple stressors. 
Table 1. North American Bat Monitoring Program Hubs and Contacts

\begin{tabular}{|c|c|c|}
\hline Hubs & States & Contact \\
\hline Mid-Atlantic & $\begin{array}{l}\text { District of Columbia, Delaware, New Jersey, } \\
\text { Maryland, Pennsylvania, Virginia, and West } \\
\text { Virginia }\end{array}$ & Jesse De La Cruz; nabat@vt.edu \\
\hline Midwest & $\begin{array}{l}\text { Illinois, Indiana, lowa, Michigan, Minnesota, } \\
\text { Missouri, Ohio, and Wisconsin }\end{array}$ & $\begin{array}{l}\text { Louis Hunnick; hunnick@illinois.edu } \\
\text { Joy O'Keefe; imokeefe@illinois.edu }\end{array}$ \\
\hline Northwest & Oregon and Washington & $\begin{array}{l}\text { Roger Rodriguez; } \\
\text { roger.rodriguez@osucascades.edu }\end{array}$ \\
\hline Pacific West & California and Nevada & Nat Goodby; ngoodby@batcon.org \\
\hline Southwest & Arizona and New Mexico & Kathy Gerst; kgerst@batcon.org \\
\hline
\end{tabular}

The following options can apply to any individual or organization interested in contributing to the NABat program. They are not specific to the wind energy industry, but the speed at which data are collected (contributing to increased quantity and diversity) and available for analysis can be increased with support by the wind energy and wildlife community.

1. Support a Hub: Partner with stakeholders to support regional hubs in coordination with the U.S. NABat Coordinating Office and identify a regional sampling strategy, regionspecific priorities, funding partners, data contributors, and means for meeting data management and reporting needs. Hubs require funding support to staff a coordinator and provide high-value services. In-kind support will enable an economy of scale that builds valuable capacity in the region. Engage with hub coordinators listed earlier to learn more or contact the NABat Coordinating Office if interested in establishing a new one.

2. Training - Data Management: Support and participate in data management trainings to smooth the process for data processing and submission to the NABat database.

3. Training - Equipment and Technology: Support and participate in trainings to educate new participants on how to conduct acoustic monitoring in their area.

4. Become a Monitoring Partner: Sample high priority cells in your region using NABat protocols. Anyone can register a project on the NABat website as a means for informing others which cells are already being monitored - this aids coordination and avoids duplication of efforts. Monitoring partners should ensure data are submitted to the NABat database.

5. Submit Data: Submit previously collected acoustic data not yet submitted to the NABat database. If data were not collected using NABat protocols, they can be submitted to the Bat Acoustic Monitoring Portal (BatAMP; https://batamp.databasin.org/) or to NABat as legacy data.

Guidance for many of these activities, ranging from setting up a new NABat project to data submission, can be found here: https://www.nabatmonitoring.org/resources. 
Specific actions for wind energy and wildlife stakeholders include transitioning from standard preconstruction acoustic monitoring to NABat monitoring, submitting previously collected data from standard preconstruction acoustic monitoring studies, or providing an "in lieu of" contribution equivalent to standard preconstruction monitoring costs.

\subsection{Genetic Analyses}

\subsubsection{Comparative studies}

There is value in comparative studies across species, geographic, and temporal scales. For example, regarding the current RADseq genomics study on hoary bats:

- Replicate the study design used by U.S. Geological Survey with eastern red bats to answer the following questions: Are the differences in estimates of genetic variation, population substructure (or lack thereof), and $\mathrm{N}_{\mathrm{e}}$ consistent with previous genetic studies? What is known about their migratory habits, reproductive biology, etc.? Do these new observations meet expectations based on what is known about their ecology and life history? If they confirm expectations, what does the "weight-of-evidence" indicate about whether these populations are stable, increasing, or decreasing? And then, how can this information be used to better inform management and mitigation strategies?

- Expand the geographic scope and temporal scale of hoary bat samples. It is possible to use historical samples to estimate the genetic parameters 15,25 , or even $50-100$ years ago. If possible, locate historical samples that can be matched by geographic location to samples collected from wind energy facilities today. Is there evidence of a decline that predates wind energy development? Are there changes in genetic diversity or $\mathrm{N}_{\mathrm{e}}$ that coincide with expansion of wind energy development over the past 20 years? How do estimates of $\mathrm{N}_{\mathrm{e}}$ and genetic diversity compare among different geographic regions that may be experiencing different levels of population stressors, such as wind energy development and climate change impacts?

Although the estimates obtained from population genetic studies will not provide direct estimates of census population sizes, they will still be informative. It is possible to use these estimates to monitor populations and population impacts over time and to make predictions about relative impacts to different species. This should be done for hoary, eastern red, and silver-haired bats.

A crucial step is to invest resources to collect genetic samples from bats collected at wind energy facilities over the next 2 years. Depending on the extent of COVID-19, which could impact planning efforts and field surveys in the short term, this could start in the summer or fall of 2021 or in the summer or fall of 2022. This collection should be targeted at two different scales that are reflected above: 1) Sample intensively in a few select geographic areas that have high expected levels of bat mortality for both hoary and eastern red bats (this will ensure a sufficient sample size for both species); and 2) Sample broadly across the United States to capture the rangewide level of impacts for hoary, eastern red, and silver-haired bats (this will ensure that we have sampled the entire population for each species).

\subsubsection{Genetic monitoring}

Taking multiple temporal samples over time makes it possible to monitor genetic changes associated with anthropogenic effects (Schwartz et al. 2007). This type of monitoring can be 
done with microsatellites and mtDNA markers, and with SNPs, with the advantage of SNPs being that the larger number of loci provide increased power to detect population subdivision if it exists and increased precision in the resulting estimates of genetic parameters. Bernger et al. (2016) used microsatellites and mtDNA markers to determine that the low genetic variation currently observed in the kākāpō (Strigops habroptilus) in New Zealand is due to a recent population bottleneck associated with European colonization. In a study using RADseq, Cammen et al. (2017) found genetic signatures of historical bottlenecks in the contemporary genomes of both gray seals (Halichoerus grypus atlantica) and harbor seals (Phoca vitulina vitulina).

Several wind energy facilities in each USFWS region should be selected for continued long-term monitoring (over 5, 10, or 20 years) of the three species of migratory tree bats with a focus on collecting tissue samples for subsequent genetic analyses (gravel pad and road searches at appropriate sites). The collection, processing, and storage of tissue samples, and carcasses if available, would require cooperation and coordination that is above and beyond standard postconstruction mortality monitoring efforts. The anticipated cost of tissue sample collection and storage are not anticipated to be a barrier to participation, but additional funding sources will be required to conduct the genetic analyses.

Options for the wind energy industry to support genetic monitoring efforts include:

1. Assessment: Identify sources of genetic material that are currently available (e.g., historical or museum specimens, tissue samples, DNA sample, DNA sequences and genome data) and identify partners who are willing to share resources and/or expertise. For the historical specimens, identify samples that can be matched geographically to areas with wind energy facilities that are able to provide contemporary samples.

2. Collect contemporary samples from wind energy facilities: Identify partners who are willing to share tissue samples or carcasses from mortality searches at wind turbines over the next 2 years. Plan to collect samples at two spatial scales: rangewide to describe levels of genetic diversity and population structure (i.e., a few samples from many locations), and more intensively at local/regional scales where it is possible to conduct comparisons with historical samples (25-50 years ago), and where future comparisons can be made ( $\sim 10$ years from now). Several repositories are being established in the Southwest and Midwest regions of the United States. In addition, Texas Christian University (TCU) is willing to store an unlimited number of tissue samples indefinitely, and up to 500 carcasses for up to 3 years.

3. Protocols and data collection: Facilitate the preparation of collection protocols and data collection kits for partners willing to collect samples.

4. Confidentiality: Identify a mechanism for confidentiality (i.e., relate data to county level or some larger geographic region) if providing locality data is a barrier to participation.

Despite challenges to assessing vital rates and determining census population size, there are sound options for ascertaining population status and trends. Through the systematic collection of acoustic and genetic data over time, a weight of evidence may improve our understanding around population stability for migratory tree-roosting bat species. This information can be leveraged to infer the influence stressors have on population stability and subsequently determine the level of 
response necessary to sustain healthy populations. While an improved understanding will have broad applications relevant beyond the wind energy-wildlife community, these efforts will provide direct benefits to this community by either 1) revealing that the population status of the species of interest is stable or growing, which may abate the need for costly measures to reduce wind turbine-related mortality; or 2) providing the information necessary to catalyze proactive and relatively moderate reduction measures in the near term to stave off more aggressive and expensive measures which may be necessary if research is delayed. 


\section{References}

Allendorf, F. W. 2017. Genetics and the conservation of natural populations: allozymes to genomes. Molecular Ecology 26:420-430.

Allendorf, F. W., P.A. Hohenlohe, and G. Luikart. 2010. Genomics and the future of conservation genetics. Nature Reviews Genetics 11:697-709.

American Wind Energy Association (AWEA). 2013. U.S. Wind Industry Fourth Quarter 2013 Market Report. https://www.awea.org/Awea/media/Resources/Publications\%20and\%20Reports/Market\%20Rep orts/AWEA-4Q2013-Wind-Energy-Industry-Market-Report_Public-Version.pdf.

American Wind Energy Association (AWEA). 2020. U.S. wind industry quarterly market report: Fourth quarter 2019. https://www.awea.org/resources/publications-and-reports/marketreports/2019-u-s-wind-industry-market-reports/4q2019 marketreport.

Arnett, E. B., E. F. Baerwald, F. Mathews, L. Rodrigues, A. Rodríguez-Durán, J. Rydell, R. Villegas-Patraca, and C. C. Voigt. 2016. Impacts of wind energy development on bats: a global perspective. In: Voigt, C. C., and T. Kingston, eds. Bats in the anthropocene: conservation of bats in a changing world. New York, NY: Springer International Publishing, 295-323. https://www.dx.doi.org/10.1007/978-3-319-25220-9_11.

Ammerman, L. K., D. N. Lee, B. A. Jones, M. P. Holt, S. J. Harrison, and S. K. Decker. 2019. High frequency of multiple paternity in eastern red bats, Lasiurus borealis, based on microsatellite analysis. Journal of Heredity 1-9. https://dx.doi.org/10.1093/jhered/esz044.

Arnett, E. B., and E. F. Baerwald. 2013. Impacts of wind energy development on bats: implications for conservation. Pages 435-456 in R. A. Adams and S. C. Pedersen, editors. Bat Evolution, Ecology and Conservation. Springer, New York, New York, USA.

Arroyo-Cabrales, J., B. Miller, F. Reid, A. D. Cuarón, and P. C. de Grammont. 2016. Lasiurus borealis. The IUCN Red List of Threatened Species 2016: e.T11347A22121017. https://dx.doi.org/10.2305/IUCN.UK.2016-1.RLTS.T11347A22121017.en.

Avise, J. C. 2000. Phylogeography: The History and Formation of Species. Harvard University Press, Cambridge, Massachusetts.

Avise, J. C., R. A. Lansman, and R. O. Shade. 1979. The use of restriction endonucleases to measure mitochondrial DNA sequence relatedness in natural populations. I. Population structure and evolution in the genus Peromyscus. Genetics 92:279-295.

Baird, A. B, J. K. Braun, M. A. Mares, J. C. Morales, J. C. Patton, C. Q. Tran, and J. W. Bickham. 2015. Molecular systematic revision of tree bats (Lasiurini): doubling the native mammals of the Hawaiian Islands. Journal of Mammalogy 96:1255-1274. 
Baird, A. B, J. K. Braun, M. D. Engstrom, A. C. Holbert, M. G. Huerta, B. K. Lim, M. A. Mares, J. C. Patton, and J. W. Bickham. 2017. Nuclear and mtDNA phylogenetic analyses clarify the evolutionary history of two species of native Hawaiian bats and the taxonomy of Lasiurini (Mammalia: Chiroptera). PloS ONE. 12:10.

Banner, K. M., K. M. Irvine, T. J. Rodhouse, D. Donner, and A. R. Litt. 2019. Statistical power of dynamic occupancy models to identify temporal change: Informing the North American Bat Monitoring Program. Ecological Indicators. 150:166-176.

Barbour, R. W., and W. H. Davis. 1969. Bats of America. University of Kentucky Press, Lexington.

Barclay, R. M. R., and L. D. Harder. 2003. Life histories of bats: life in the slow lane. Pages 209-253 in T. H. Kunz and M. B. Fenton, eds. Bat ecology. The University of Chicago Press, IL.

Bergner, L. M., N. Dussex, I. G. Jamieson, and B. C. Robertson. 2016. European colonization, not Polynesian arrival, impacted population size and genetic diversity in the critically endangered New Zealand kākāpō. Journal of Heredity 107:597-602.

Brown, W. M., and J. W. Wright. 1979. Mitochondrial DNA analysis and the origin and relative age of parthenogenetic lizards (genus Cnemidophorus). Science 203:1247-1249.

Canadian Wind Energy Association (CanWEA). 2020. www.canwea.ca.

Carter, T. C., M. A. Menzel, and D. A. Saugey. 2003. Population trends of solitary foliageroosting bats. In T. J. O'Shea and M. A. Bogan, editors. Monitoring trends in bat populations of the United States and territories: problems and prospects. U. S. Geological Survey Biological Resources Division, Information and Technology Report. Washington, D.C.

Cheng, T. L., J. D. Reichard, J. T. H. Coleman, T. J. Weller, W. E. Thogmartin, B. E. Reichert, A. Bennett, H. G. Broders, J. Campbell, K. Etchison, D. J. Feller, R. Beboy, T. Hemberger, C. Herzog, A. C. Hicks, S. Houghton, J. Humber, J. A. Kath, A. King, S. C. Loeb, A. Masse, K. M. Morris, H. Niederriter, G. E. Nordquist, R. W. Perry, R. Reynolds, D. B. Sasse, M. R. Scafini, R. C. Stark, C. W. Stihler, S. C. Thomas, G. C. Turner, S. Webb, B. Westrich, W. F. Frick. Forthcoming. The scope and severity of white-nose syndrome on hibernating bats in North America. Conservation Biology.

Chipps, A., A. M. Hale, S. P. Weaver, and D. A. Williams. 2020a. Genetic approaches are necessary to accurately understand bat-wind turbine impacts. Diversity 12:236. https://www.dx.doi.org/10.3390/d12060236.

Chipps, A. S., A. M. Hale, S. P. Weaver, and D. A. Williams. 2020b. Genetic diversity, population structure, and effective population size in two yellow bats species in south Texas. PeerJ 8:e10348. https://www.dx.doi.org/10.7717/peerj.10348.

Coates, D. J., M. Byrne, and C. Moritz. 2018. Genetic diversity and conservation units: dealing with the species-population continuum in the age of genomics. Frontiers in Ecology \& Evolution 6:165. 
Cochran, W. G. 1977. Sampling Techniques, $3^{\text {rd }}$ Edition. New York, NY. Wiley Press.

Dobrynin, P., S. Liu, G. Tamazian, et al. 2015. Genomic legacy of the African cheetah, Acinonyx jubatus. Genome Biology 16:1-20.

Dool, S. E. 2020. Conservation genetic studies in bats. Pp. 29-64 in Conservation Genetics in Mammals - Integrative Research Using Novel Approaches, J. Ortega \& J. E. Maldonado (eds.). Springer, Switzerland.

Electrical Power Research Institute (EPRI). 2020. Population-level risk to hoary bats amid continued wind energy development: Assessing fatality reduction targets under broad uncertainty. EPRI, Palo Alto, CA. Final report 3002017671.

Ellegren, H. 2014. Genome sequencing and population genomics in non-model organisms. Trends in Ecology \& Evolution 29:51-63

Erickson, R. A., W. E. Thogmartin, and J. A. Szymanski. 2014. BatTool: an R package with GUI for assessing the effect of White-nose syndrome and other take events on Myotis spp. of bats. Source Code for Biology and Medicine 9:9. https://scfbm.biomedcentral.com/articles/10.1186/1751-0473-9-9.

Findley, J. S. 1993. Bats: a community perspective. Cambridge University Press, Cambridge, MA.

Forcina, G., and J. A. Leonard. 2020. Tools for monitoring genetic diversity in mammals: past, present, and future. Pp. 13-28 in Conservation Genetics in Mammals - Integrative Research Using Novel Approaches, J. Ortega \& J. E. Maldonado (eds.). Springer, Switzerland.

Ford, W. M., E. R. Britzke, C. A. Dobony, J. L. Rodrigue, and J. B. Johnson. 2011. Patterns of acoustical activity of bats prior to and following white-nose syndrome occurrence. Journal of Fish and Wildlife Management 2:125-134.

Francl, K. E., W. M. Ford, D W. Sparks, and V. Brack, Jr. 2012. Capture and reproductive trends in summer bat communities in West Virginia: assessing the impact of white-nose syndrome. Journal of Fish and Wildlife Management 3:33-42.

Frankham, R., J. D. Ballou, and D. A. Briscoe. 2009. Introduction to Conservation Genetics, Second Edition. Cambridge University Press, New York, New York, USA.

Frick, W. F., J. F. Pollock, A. C. Hicks, K. E. Langwig, D. S. Reynolds, G. G. Turner, C. M. Butchkoski, and T. H. Kunz. 2010. An emerging disease causes regional population collapse of a common North American bat species. Science 329: 679-682.

Frick, W. F., S. J. Puechmaille, J. R. Hoyt, B. A. Nickel, K. E. Langwig, J. T. Foster, K. E. Barlow, T. Bartonicka, D. Feller, A. Haarsma, C. Herzog, I. Horacek, J. van der Kooij, B. Mulkens, B. Petrov, R. Reynolds, L. Rodriques, C. W. Stihler, G. G. Turner, A. M. Kilpatrick 2015. Disease alters macroecological patterns of North American bats. Global Ecology and Biogeography 24:741-49. https://doi.org/10/ggb7qi. 
Frick, W. F., E. F. Baerwald, J. F. Pllock, R. M. R. Barclay, J. A. Szymanski, T. J. Weller, A. L. Russell, S. C. Loeb, R. A. Medellin, and L. P. McGuire. 2017. Fatalities at wind turbines may threaten population viability of a migratory bat. Biological Conservation 209:172-177.

Frick, W. F., T. Kingston, and J. Flanders. 2019. A review of the major threats and challenges to global bat conservation. Annals of the New York Academy of Sciences. 1-21.

Gitzen, R. A., and J. J. Millspaugh. 2012. Ecological monitoring: the heart of the matter. Pages 3-22 in R. A. Gizen, J. J. Millspaugh, A. B. Cooper, D. S. Licht, eds. Design and analysis of long-term ecological monitoring studies. Cambridge University Press, New York.

Goldstein, D.B., and D. D. Pollock. 1997. Launching microsatellites: a review of mutation processes and methods of phylogenetic inference. Journal of Heredity 88:335-342.

Gonzalez, E., R. Barquez, and J. Arroyo-Cabrales. 2016. Lasiurus cinereus. The IUCN Red List of Threatened Species 2016: e.T11345A22120305. https://dx.doi.org/10.2305/IUCN.UK.20161.RLTS.T11345A22120305.en.

Green, R. H. 1979. Sampling design and statistical methods for environmental biologists. New York, NY. John Wiley and Sons.

Gregory, A. J., R. S. A. Kaler, T. J. Prebyl, B. K. Sandercock, and S. M. Wisely. 2012. Influence of translocation strategy and mating system on the genetic structure of a newly established population of island ptarmigan. Conservation Genetics 13:465-474.

Grodzinski, U., O. Spiegel, C. Korine, and M. W. Holderied. 2009. Context-dependent flight speed: evidence for energetically optimal flight speed in the bat Pipistrellus kuhlii? Journal of Animal Ecology. 78:540-548.

Hall, E. R. 1946. Mammals of Nevada. University of California Press. Berkeley, CA.

Hallmann, C. A., M. Sorg, E. Jongejans, H. Siepel, N. Hofland, H. Schwan, W. Stenmans, A. Müller, H. Sumser, T. Hörren, D. Goulson, and H. de Kroon. 2017. More than 75 percent decline over 27 years in total flying insect biomass in protected areas. PLoS ONE 12 (10): e0185809.

Hayes, J. P., H. K. Ober, R. E. Sherwin. 2009. Survey and monitoring of bats. Pages 112-129 in Kunz, T. H., and Parsons, S. eds. Ecological and behavioral methods for the study of bats, $2^{\text {nd }}$ edition. Baltimore, MD. Johns Hopkins University Press.

Hayes, M. A. 2013. Bats killed in large numbers at United States wind energy facilities. BioScience 63:975-979.

Hayward, B., and R. Davis. 1964. Flight speeds in western bats. Journal of Mammalogy 45:236242.

Henderson, L. E., and H. G. Broders. 2008. Movements and resource selection of the northern long-eared myotis (Myotis septentrionalis) in a forest-agriculture landscape. Journal of Mammalogy 89:952-963. 
Hohenlohe, P.A., S. Bassham, P. D. Etter, et al. 2010. Population genomic analysis of parallel adaptation in threespine stickleback using sequenced RAD tags. PLoS Genetics 6:e1000862.

Howell, A. H. 1908. Notes on diurnal migrations of bats. Proceedings of the Biological Society of Washington 21:35-38.

Jeffreys, A. J., W. Wilson, and S. L. Thein. 1985. Hypervariable 'minisatellite' regions in human DNA. Nature 314:67-73.

Jennings, W. L. 1958. The ecological distribution of bats in Florida. Ph.D. Dissertation, University of Florida, Gainsville.

Jones, G., D. S. Jacobs, T. H. Kunz, M. R. Willig, and P. A. Racey. 2009. Carpe noctem: the importance of bats as bioindicators. Endangered Species Research. 8:93-115.

Kennedy, M. L., and T. L. Best. 1972. Flight speed of the gray bat, Myotis grisescens. Journal of Mammalogy 88:254-255.

Kirk, H., and J. R. Freeland. 2011. Applications and implications of neutral versus non-neutral markers in molecular ecology. International Journal of Molecular Sciences. 12:3966-3988.

Koepfli, K-P., and R. M. Gooley. 2020. A modern synthesis of mammal conservation genetics. Pp. 3-12 in Conservation Genetics in Mammals - Integrative Research Using Novel Approaches, J. Ortega \& J. E. Maldonado (eds.). Springer, Switzerland.

Korstian, J. M., A. M. Hale, and D. A. Williams. 2015. High genetic diversity, large historic population size, and lack of population structure in 2 North American tree bats. Journal of Mammalogy 96:972-980.

Kunz, T. H, E. B. Arnett, W. P. Erickson, A. R. Hoar, G. D. Johnson, R. P. Larkin, M. D. Strickland, R. W. Thresher, and M. D. Tuttle. 2007. Ecological Impacts of wind energy development on bats: questions, research needs, and hypotheses. Frontiers in Ecology and the Environment 5:315-324.

Langwig, K. E., W. F. Frick, J. T. Bried, A. C. Hicks, T. H. Kunz, and A. M. Kilpatrick. 2012. Sociality, density-dependence and microclimates determine the persistence of populations suffering from a novel fungal disease, White-nose Syndrome. Ecology Letters 15: 1050-57. https://doi.org/10/f35qfq.

Lage, C., and I. Kornfield. 2006. Reduced genetic diversity and effective population size in an endangered Atlantic salmon (Salmo salar) population from Maine, USA. Conservation Genetics 7:91-104.

Larsen, D. P., A. R. Olsen, and D. L. Stevens, Jr. 2008. Using a master sample to integrate stream monitoring program. Journal of Agricultural, Biological, and Environmental Statistics. $13: 243-254$. 
LaVal R. K., and M. L. LaVal. 1979. Notes on reproduction, behavior, and abundance of the red bat, Lasiurus borealis. Journal of Mammalogy. 60:209-212.

Leigh, D. M., A. P. Hendry, E. Vázquez-Domínguez, and V. L. Friesen. 2019. Estimated six percent loss of genetic variation in wild populations since the industrial revolution. Evolutionary Applications 12:1505-1512.

Lentini, P. E., T. J. Bird, S. R. Griffiths, L. N. Godinho, and B. A. Wintle. 2015. A global synthesis of survival estimates for microbats. Biological Letters 11:20150371. http://dx.doi.org/10.1098/rsbl.20150371.

Loeb, S. C., E. R. Britzke, J. T. H. Coleman, L. Ellison, T. Rodhouse, M. Vonhof, S. Amelon, P. Cryan, C. Hein, M. Kilpatrick, P. Ormsbee, A. Russell, T. Stanley, W. Thogmartin, and T. Weller. 2012. Bat population monitoring and modeling workshop: final report of proceedings and recommendations. U. S. Fish and Wildlife Service, Hadley, MA.

Loeb, S. C., T. J. Rodhouse, L. E. Ellison, C. L. Lausen, J. D. Reichard, K. M. Irvine, T. E. Ingersoll, J. T. H. Coleman, W. E. Thogmartin, J. R. Sauer, C. M. Francis, M. L. Bayless, T. R. Stanley, and D. H. Johnson. 2015. A plan for the North American bat monitoring program (NABat). U. S. Forest Service General Technical Report SRS-208.

Luikart, G. H., P. England, D. A. Tallmon, S. Jordan, and P. Taberlet. 2003. The power and promise of population genomics: from genotyping to genome-typing. Nature Reviews Genetics 4:981-994.

Mackenzie D. I., J. D. Nichols, J. A. Royle, K. H. Pollock, L. L. Bailey, and J. E. Hines. 2006. Occupancy estimation and modeling: inferring patterns and dynamics of species occurrence. Academic Press. New York.

McCartney-Melstad, E., J. K. Vu, and H. B. Shaffer. 2018. Genomic data from an endangered amphibian reveal unforeseen consequences of fragmentation by roads. bioRxiv. https://doi.org/10.1101/306340.

Mearns, E. A. 1898. A study of the vertebrate fauna of the Hudson Highlands, with observations on the Mollusca, Crustacea, Lepidoptera, and the flora of the region. Bulletin of the American Museum of Natural History 10:303-352.

Miller, G. S. 1897. Migration of bats on Cape Cod, Massachusetts. Science 5:541-543.

Morin, P. A., G. Luikart, and R. K. Wayne, SNP Workshop Group. 2004. SNPs in ecology, evolution and conservation. Trends in Ecology \& Evolution 19:208-216.

Morrell, T. E., M. J. Rabe, J. C. deVos Jr., H. Green, and C. R. Miller. 1999. Bats captured in two ponderosa pine habitats in north-central Arizona. The Southwestern Naturalist 44:501-506.

Neece, B. D., D. S. Jachowski, and S. C. Loeb. 2019. Implementing and assessing the efficacy of the North American Bat Monitoring Program. Journal of Fish and Wildlife Management 10:391409. 
Novaes, R. L. M., G. S. T. Garbino, V. C. Cláudio, and R. Moratelli. 2018. Separation of monophyletic groups into distinct genera should consider phenotypic discontinuities: the case of Lasiurini (Chiroptera: Vespertilionidae). Zootaxa. https://doi.org/10.11646/zootaxa.4379.3.8.

O’Donnell, C. F. J. 2009. Population dynamics and survivorship in bats. Pages 158-176 in T. H. Kunz and S. Parsons, eds. Ecological and behavioral methods for the study of bats, $2^{\text {nd }}$ edition. Johns Hopkins University Press, Baltimore, MD.

Olsen, A. R., J. Sedransk, D. Edwards. 1999. Statistical issues for monitoring ecological and natural resources in the United States. Environmental Monitoring and Assessment 54:1-45.

O’Shea, T. J., M. A. Bogan eds. 2003. Monitoring trends in bat populations of the United States and territories: problems and prospects. Reston, VA. U. S. Geological Survey, Biological Resources Division, Information and Technology Report. Washington, D.C.

O’Shea, T. J., L. E., Ellison, and T. R. Stanley. 2004. Survival estimation in bats: historical overview, critical appraisal, and suggestions for new approaches. Pages 297-336 in W. L. Thompson, ed, Sampling Rare or Elusive Species. Island Press, Washington, D. C.

O’Shea, T. J., P. M. Cryan, D. T. S. Hayman, R. K. Plowright, and D. G. Steicker. 2016. Multiple mortality events in bats: a global review. Mammal Review 46:175-190.

Patterson, A. P., and J. W. Hardin. 1969. Flight speeds of five species of vespertilionid bats. Journal of Mammalogy 50:152-153.

Pearse, D. E., and E. C. Anderson. 2009. Multiple paternity increases effective population size. Molecular Ecology 18:3124-3127.

Pevsner, J. 2015. Bioinformatics and Functional Genomics, $3^{\text {rd }}$ Edition. John Wiley \& Sons, Inc., West Sussex, UK.

Podlutsky, A. J., A. M. Khritankov, N. D. Ovodov, and S. N. Austad. 2005. A new field record for bat longevity. Journal of Gerontology 60:1366-1368.

Pylant, C. L., D. M. Nelson, M. C. Fitzpatrick, J. E. Gates, and S. R. Keller. 2016. Geographic origins and population genetics of bats killed at wind-energy facilities. Ecological Applications 26:1381-1395.

Reichert, B. E., Bayless, M., Cheng, T. L., J. T. H. Coleman, C. M. Francis, W. F. Frick, B. S. Gotthold, K. M. Irvine, C. Lausen, H. Li, S. C. Loeb, J. D. Reichard, T. J. Rodhouse, J. L.

Segers, J. L. Siemers, W. E. Thogmartin, T. J. Weller. 2021. NABat: A top-down, bottom-up solution to collaborative continental-scale monitoring. Ambio. https://doi.org/10.1007/s13280020-01411-y.

Richardson, S. M., P. R. Lintott, D. J. Hosken, T. Economou, and F. Mathews. 2021. Peaks in bat activity at turbines and the implications for mitigating the impact of wind energy

developments on bats. Scientific Reports. https://doi.org/10.1038/s41598-021-82014-9. 
Roche, N., C. Catto, S. Langton, T. Aughney, and J. Russ. 2005. Development of a car-based bat monitoring protocol for the Republic of Ireland. Irish Wildlife Manuals, No.19. National Parks and Wildlife Service, Department of Environment, Heritage and Local Government, Dublin, Ireland, $42 \mathrm{pp}$.

Roche, N., S. Langton, T. Aughney, J. M. Russ, F. Marnell, D. Lynn, and C. Catto. 2011. A carbased monitoring method reveals new information on bat populations and distributions in Ireland. Animal Conservation 14:642-651.

Rodhouse, T. J., K. T. Vierling, K. M. Irvine. 2011. A practical sampling design for acoustic surveys of bats. Journal of Wildlife Management 75:1094-1102.

Rodhouse, T. J., R. M. Rodriguez, K. M. Banner, P. C. Ormsbee, J. Barnett, and K. M. Irvine. 2019. Evidence of region-wide bat population decline from long-term monitoring and Bayesian occupancy models with empirically informed priors. Ecology and Evolution. https://dx.doi.org/10.1002/ece3.5612.

Sánchez-Bayo, F. and K. A. G. Wyckhuys. 2019. Worldwide decline of the enotmofauna: a review of its drivers. Biological Conservation 232:8-27.

Schaub, A., and H. U. Schnitzler. 2007. Flight and echolocation behavior of three vespertilionid bat species while commuting on flyways. Journal of Comparative Physiology A 193:1185-1194.

Schwartz, M. K., G. Luikart, and R. S. Waples. 2007. Genetic monitoring as a promising tool for conservation and management. Trends in Ecology \& Evolution 22:25-33.

Sherwin, H. A., W. I. Montgomery, and M. G. Lundy. 2013. The impact and implications of climate change for bats. Mammal Review 43:171-182.

Selander, R. K. 1976. Genic variation in natural populations. In: Molecular Evolution (ed. Ayala FJ), pp. 21-45. Sinauer Associates, Sunderland, Massachusetts.

Smallwood, K. S. 2013. Comparing bird and bat fatality-rate estimates among North American wind-energy projects. Wildlife Society Bulletin 37:19-33.

Solari, S. 2019. Lasionycteris noctivagans. The IUCN Red List of Threatened Species 2019:

e.T11339A22122128. https://dx.doi.org/10.2305/IUCN.UK.20191.RLTS.T11339A22122128.en.

Solick, D., D., Pham, K. Nasman, and K. Bay. 2020. Bat activity rates do not predict bat fatality rates at wind energy facilities. Acta Chiropterologica 22: 135-146.

Sovic, M. G., B. C. Carstens, and H. L. Gibbs. 2016. Genetic diversity in migratory bats: results from RADseq data for three tree bat species at an Ohio windfarm. PeerJ 4:e1647. https://doi.org/10.7717/peerj.1647.

Stevens, D. L., and A. R. Olsen. 2004. Spatially balanced sampling of natural resources. Journal of the American Statistical Association 99:262-278. 
Sugg, D. W., and R. K. Chesser. 1994. Effective population sizes with multiple paternity. Genetics 137:1147-1155.

Supple, M. A., and B. Shapiro. 2018. Conservation of biodiversity in the genomics era. Genome Biology 19:131. https://doi.org/10.1186/s13059-018-1520- .

Teeling, E. C., S. C. Vernes, L. M. Dávalos, D. A. Ray, M. T. P. Gilbert, E. Myers, Bat1K Consortium. 2018. Bat biology, genomes, and the Bat $1 \mathrm{~K}$ project: to generate chromosome-level genomes for all living bat species. Annual Review of Animal Biosciences 6:23-46. https://doi.org/10.1146/annurev-animal-022516-022811.

Thogmartin, W. E., C. Sanders-Reed, J. A. Szymanski, R. A. King, L. Pruitt, P. C. McKann, M. C. Runge, and R.E. Russell. 2013. White-nose syndrome is likely to extirpate the endangered Indiana bat over large parts of its range. Biological Conservation 160:162-172.

Thompson, S. K. 2002. Sampling, $2^{\text {nd }}$ edition. Wiley Press, New York, NY.

Turner, G. G., D. M. Reeder, and J. T. H. Coleman. 2011. A five-year assessment of mortality and geographic spread of white-nose syndrome in North American bats and a look to the future. Bat Research News 52:13-27.

U.S. Department of Energy 2015. Wind vision: a new era for wind power in the United States. USDOE Office of Scientific and Technical Information Report DOE/GO-102015-4557. Oak Ridge, TN.

Vaughn, T. A. 1953. Unusual concentration of hoary bats. Journal of Mammalogy 34:356.

Vonhof, M. J., and A. L. Russell. 2015. Genetic approaches to the conservation of migratory bats: a study of the eastern red bat (Lasiurus borealis). PeerJ 3:e983. http://doi.org/10.7717/peerj.983.

Whitaker, J. O., Jr., V. Brack, and J. B. Cope. 2002. Are bats in Indiana declining? Proceedings of the Indiana Academy of Science 111:95-106.

Whitby, M. D., T. C. Carter, E. R. Britzke, and S. M. Bergeson. 2014. Evaluation of mobile acoustic techniques for bat population monitoring. Acta Chiropterologica 16:223-230.

Winhold, L., A. Kurta, and R. Foster. 2008. Long-term change in an assemblage of North American bats: are eastern red bats declining? Acta Chiropterologica 10:359-366.

Wiser, R., Z. Yang, M. Hand, O. Hohmeyer, D. Infield, P. H. Jensen, V. Nikolaev, M. O'Malley, G. Sinden, and A. Zervos. 2011. Wind Energy. In IPCC special report on renewable energy courses and climate change mitigation. Edenhofer, O., R. Pichs-Madruga, Y. Sokona, K. Seyboth, P. Matschoss, S. Kadner, T. Zwickel, P. Eickemeier, G. Hansen, S. Schlomer, and C. von Stechow eds. Cambridge University Press, Cambridge, United Kingdom, and New York, United States. 
Zimmerling, J. R., and C. M. Francis. 2016. Bat mortality due to wind turbines in Canada. Journal of Wildlife Management 80:1360-1369. 